\title{
PARTICLE SHAPE EFFECT ON MACROSCOPIC BEHAVIOUR OF UNDERGROUND STRUCTURES: NUMERICAL AND EXPERIMENTAL STUDY
}

\author{
KRZYSZTOF SZARF \\ Faculty of Civil and Environmental Engineering, Gdańsk University of Technology, Gdańsk, Poland. \\ GAËL COMBE, PASCAL VILLARD \\ Laboratoire 3SR, Université de Grenoble/CNRS, Grenoble, France, \\ e-mail: krzysztof.szarf@pg.gda.pl,gael.combe@3sr-grenoble.fr, pascal.villard@ujf-grenoble.fr
}

\begin{abstract}
The mechanical performance of underground flexible structures such as buried pipes or culverts made of plastics depend not only on the properties of the structure, but also on the material surrounding it. Flexible drains can deflect by $30 \%$ with the joints staying tight, or even invert. Large deformations of the structure are difficult to model in the framework of Finite Element Method, but straightforward in Discrete Element Methods. Moreover, Discrete Element approach is able to provide information about the grain-grain and grain-structure interactions at the microscale. This paper presents numerical and experimental investigations of flexible buried pipe behaviour with focus placed on load transfer above the buried structure. Numerical modeling was able to reproduce the experimental results. Load repartition was observed, being affected by a number of factors such as particle shape, pipe friction and pipe stiffness.
\end{abstract}

Key words: discrete element method, particle shape, underground pipe, digital image correlation

\section{INTRODUCTION}

Underground pipes are widely used in various fields of engineering. Typical pipe applications include the transport of fluids under pressure (oil, gas, water) or with a free surface (sewage, drain water). Moreover, large pipes are often used as tunnels or culverts that allow water flow and animal crossing through embankments. Historically buried pipes were made of materials such as bricks or steel and were constructed thick and stiff in order to carry the external loads with the strength of the pipe itself. In modern times, the introduction of new materials like plastics or sheet steel allowed flexible constructions with thinner walls to be constructed. Such flexible pipes carry the load in cooperation with the surrounding soil and therefore the question of soil-structure interaction is essential for its design. The nature of that cooperation is based on the load transfer above the buried pipes which is linked to the arching effect in the backfill soil.

The study presented in this paper was focused on experimental and numerical investigations of the load transfer above flexible buried unpressurised pipe. Flexible buried pipes deflect under load and depending on the particular application can deflect beyond $30 \%$ of diameter or even invert while remaining hydraulically operational. Such large deformations can be difficult to model in the framework of Finite Element Method (FEM) but are natural for even the most basic Discrete Element codes (DEM). Moreover, in order to study the load transfer one needs access to interparticle forces at the microscale, which are available in DEM as well.

In this work, we performed laboratory experiments on PVC pipes surrounded by 2D analogue soil, and subsequently modeled the same problem in DEM.

\section{EXPERIMENTAL PROGRAM}

The experiments on buried pipes were performed using the $1 \gamma 2 \varepsilon$ apparatus, Fig. 1, located in 3SR Laboratory in Grenoble, France. The apparatus was used and described numerous times (Joer et al. [6]; Cal- 
vetti et al. [1]; Sibille and Froiio [11]; Hall et al. [5]; Lirer et al. [7]; Charalampidou et al. [3]). $1 \gamma 2 \varepsilon$ is able to impose different plane stress loading conditions on 2D analogue Schneebeli material (Schneebeli [10]). In this work, two types of analogue soil were used: wooden rods with diameters ranging from 0.8 to $2.0 \mathrm{~cm}$ and PVC rods with diameters between 0.1 and $0.3 \mathrm{~cm}$, Fig. 2b. All the rods were circular and $6.0 \mathrm{~cm}$ long. Apart from the rods, $6.0 \mathrm{~cm}$ long pieces of commer- cially available PVC pipe with external diameter of $10.0 \mathrm{~cm}$ were used, Fig. $2 \mathrm{a}$.

Two types of experiments were performed: with or without the flexible pipe buried in the granular material. In every case the granular sample was placed inside the apparatus, one handful at a time, and subjected to vertical compression test with constant lateral loading, preceded by isotropic loading with $\sigma=$ $50 \mathrm{kPa}$. The samples were loaded with rigid, smooth

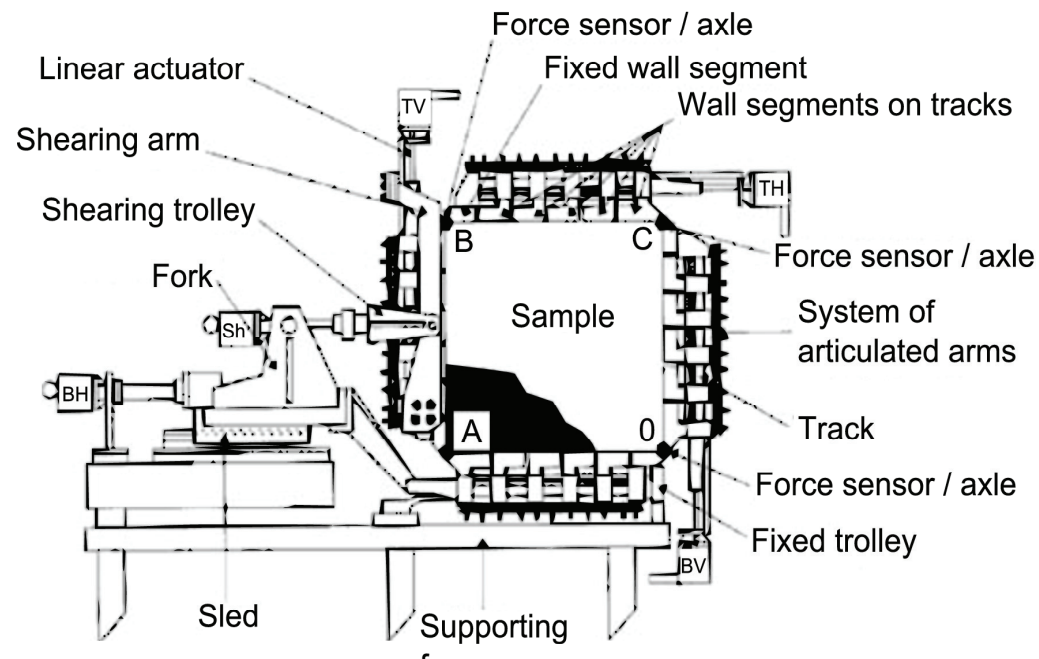

Fig. 1. Sketch of the $1 \gamma 2 \varepsilon$ apparatus

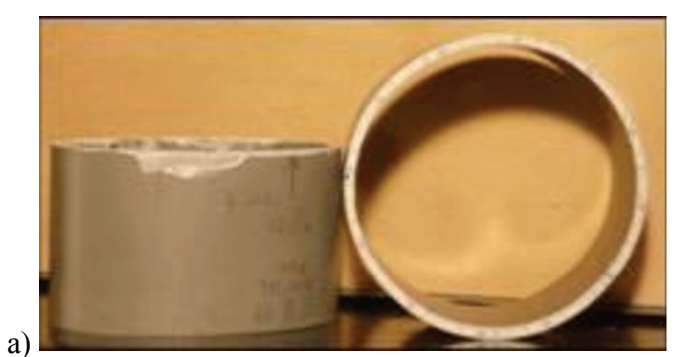

b)
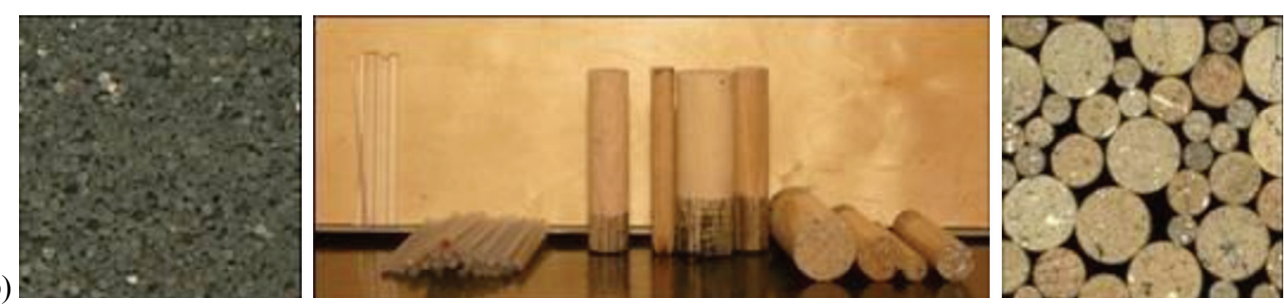

Fig. 2. The materials used in the $1 \gamma 2 \varepsilon$ experiments: (a) flexible PVC pipe; $d=10.0 \mathrm{~cm}, t=0.33 \mathrm{~cm}$; (b) granular material: PVC grains (left), wooden grains (right). The length of all the elements was $6.0 \mathrm{~cm}$

Description of the $1 \gamma 2 \varepsilon$ experiments

\begin{tabular}{|c|c|c|c|c|}
\hline Material & Pipe & Load velocity & Image interval & Test name \\
\hline PVC & no & $2.0 \mathrm{~cm} / \mathrm{h}$ & none & Biax-1-PVC-NoPipe \\
\hline Wood & no & $2.5 \mathrm{~cm} / \mathrm{h}$ & none & Biax-2-Wood-NoPipe \\
\hline Wood & yes & $2.5 \mathrm{~cm} / \mathrm{h}$ & $30 \mathrm{~s}$ & Biax-3-Wood-Pipe \\
\hline PVC & yes & $5.1 \mathrm{~cm} / \mathrm{h}$ & $30 \mathrm{~s}$ & Biax-4-PVC-Pipe \\
\hline
\end{tabular}


walls of the apparatus. During the tests the external forces imposed on the sample were measured with transducers located in the hinges connecting the apparatus walls while the wall displacements were recorded using four LVDTs, see Fig. 1. Due to the fact that the front face of the sample was unobstructed and flat, it was possible to take digital images throughout the tests and then to analyse it with Digital Image Correlation techniques (DIC). The approximate initial size of the entire granular sample was $60 \times 60 \mathrm{~cm}$; Each sample contained about 2000 wooden rods or 40000 PVC rods. The four experiments performed are summarised in Table 1.

\subsection{DIGITAL IMAGE CORRELATION TECHNIQUE}

The measurements of global stresses and strains of the sample in $1 \gamma 2 \varepsilon$ were enhanced with DIC (Sutton et al. [12]; Richefeu et al. [9]).

The method consists of finding a matching motif in two images, Fig. 3. A node is defined in the reference image $n$. Around the node a correlation window containing some characteristic features of the image, like for example specimen surface texture, is defined. The motif inside the correlation window is searched for in the second image $n+1$ within some area called a search range. The motif is compared with various fragments of the image and each comparison is quantified with a correlation coefficient. Finally a displacement vector can be drawn between the initial and final position of the node.

The tests in $1 \gamma 2 \varepsilon$ were photographed every $30 \mathrm{~s}$ using a $24 \mathrm{Mpx}$ digital camera connected to a computer. Using the sets of photographs it was possible to observe the kinematics of the granular material, the pipe and the apparatus itself. The front surface of the PVC pipe was painted white, and sprayed with a fine pattern of random dots. 48 characteristic points equally distributed on the perimeter of the pipe were followed through the tests. Tracking of the granular material was done in two ways: in the case of wooden rods the diameter of the particles was large enough to fit a correlation window inside a single rod and follow each particle independently once the front surface of the rods was painted with contrasting black and white speckles; in the case of PVC grains the diameter of such a rod was about $9 \mathrm{px}$ which was not enough to perform direct grain tracking. Instead a regular grid of nodes was placed across the whole granular sample and tracked throughout the tests. The natural contrast of the PVC rods was enough to perform DIC without additional grain painting. Apart from the automated tracking of the granular material and the pipe segments, the corners of the $1 \gamma 2 \varepsilon$ apparatus were followed as well in order to assure the accuracy of LVDT measurements. Finally, two additional reference points disconnected from the apparatus were followed as well to compensate for camera movement errors. The DIC technique is very sensitive in terms of image quality so it was important to provide homogeneous lighting of the photographed surface of the sample.

\section{2. $1 \gamma 2 \varepsilon$ EXPERIMENTAL RESULTS}

The measurements provided by the sensors of the apparatus gave access to macroscopic stresses and strains of the sample. In the figure 4 the results of vertical compression tests with and without PVC pipe on two different types of granular materials are given. It appears that the presence of the flexible pipe had little effect on the macroscopic behaviour of the samples. In case of PVC samples, Fig. 4a, tests with and without the pipe are similar both at the peak and at the residual values of vertical stress. The behaviour of the
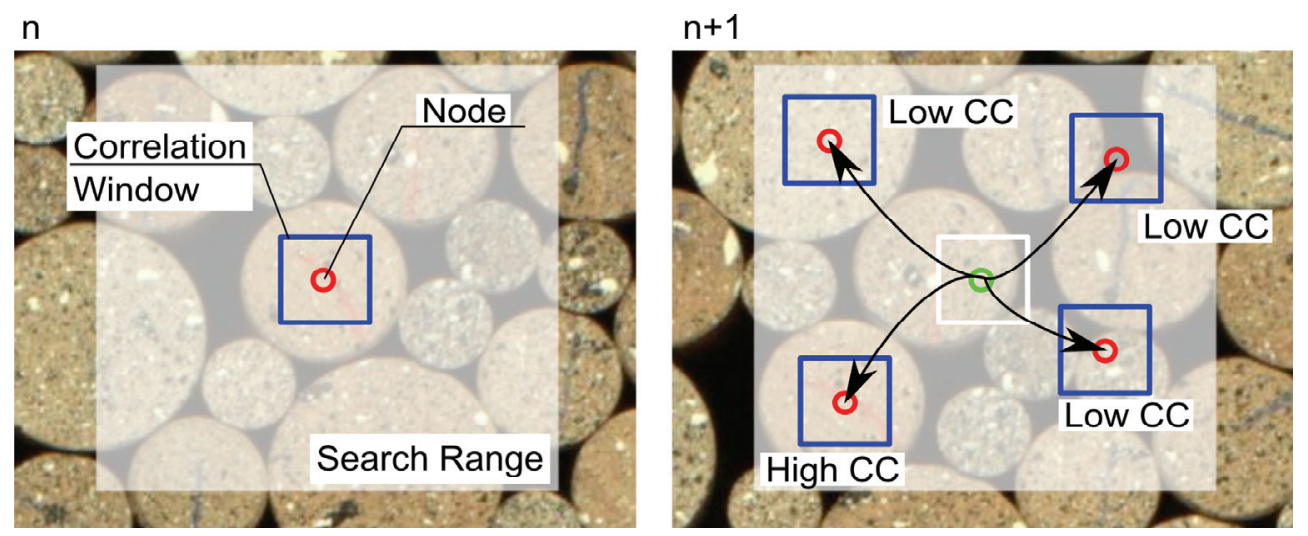

Fig. 3. Digital Image Correlation principle. A given wooden rod is searched for after rearrangement of the medium 
sample in terms of volumetric strains was similar as well, considering that it varies from test to test depending on random initial arrangement of the granular material. The comparison of the two tests with wooden particles, Fig. 4b, reveals a difference in the maximum level of vertical stress. It should be noted that during these tests due to the large size and small number of the particles occasionally some rapid movements of the rods occured which were related to closing of rather large voids in the assembly and caused sudden drop of stresses. Because of that, the macroscopic curves of tests performed on wooden rods are generally speaking more chaotic than the ones obtained with PVC.

The lack of influence of soft and rigid inclusions on the macroscopic behaviour of sand was previously noted by Desrues and Viggiani [4].

Observations of the pipe buried in granular material during vertical loading revealed that the pipe sur- rounded with small PVC particles deformed in a symmetrical manner while the pipe in wooden analogue soil deformed asymmetrically, see Fig. 5. That difference was caused by the number of particles in contact with the pipe surface and therefore the uniformity of forces acting on the pipe.

The pipe shape was tracked with DIC at 48 points on its front face and therefore it was possible to compute the mezoscopic change of cross-section area of the pipe $\varepsilon_{V}=\frac{A_{1}-A_{2}}{A_{1}}$ and relate it to the volumetric strains of the whole assembly, Fig. 6. While the granular assembly was dilating, as seen in Fig. 4 or Fig. 6, the flexible pipe was contracting. Another remark can be made that the change of pipe area obtained in the physical experiments, even though asymmetrical, was in accord with the change of area of a circle compressed to an ellipse, see Fig. 7.
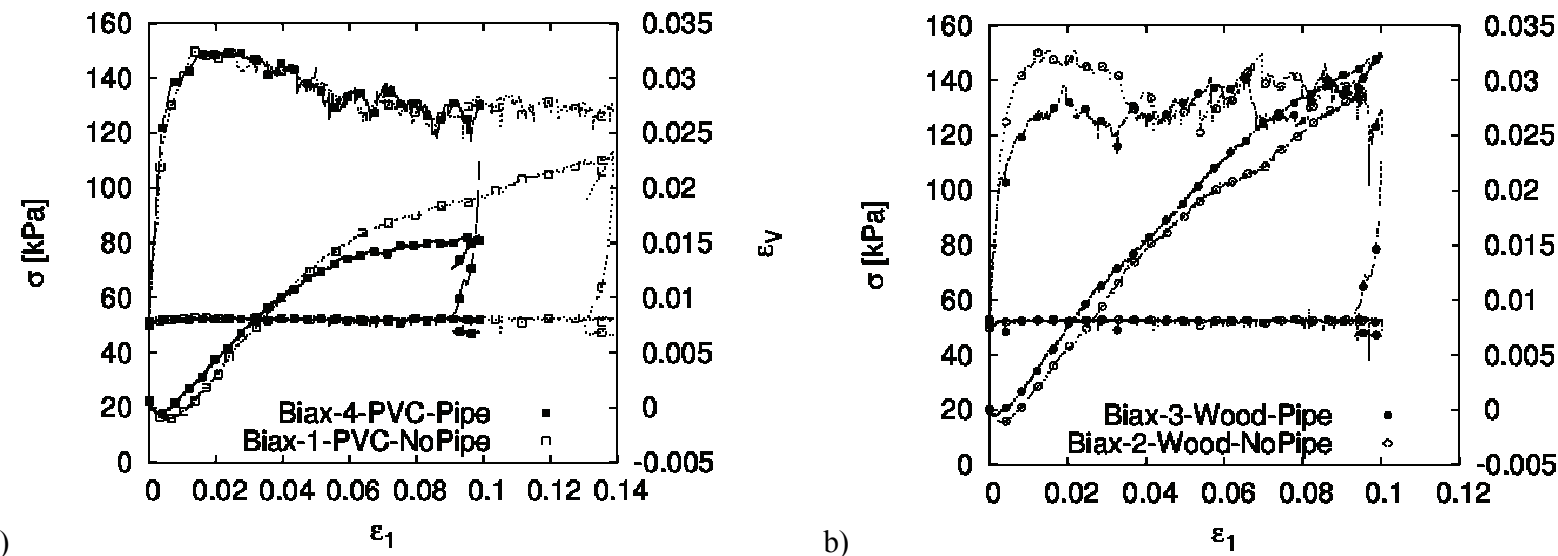

Fig. 4. $1 \gamma 2 \varepsilon$ experiment results of two types of materials with or without a circular, flexible pipe inside: (a) PVC rods; (b) wooden rods. The horizontal stress was kept constant at $50 \mathrm{kPa}$, while the vertical stress rose to a peak, decreased and stabilised. The change of volume (area) of the sample is typical of a dense assembly of cohesionless grains

a)

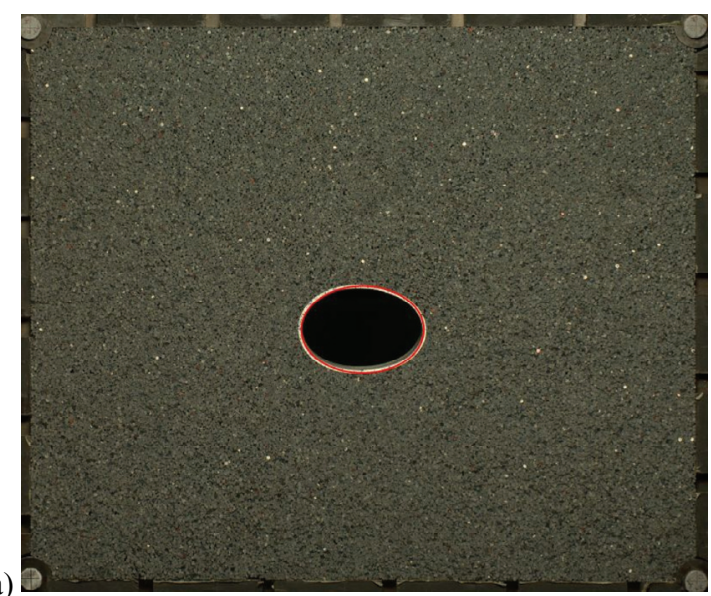

b)

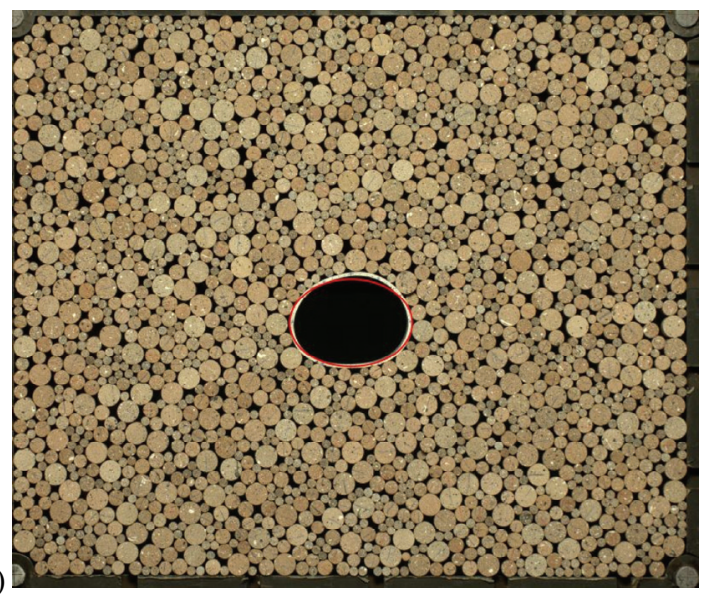

Fig. 5. Images of the loaded samples: (a) PVC rods; (b) Wooden rods. A red ellipse with the same value of eccentricity 


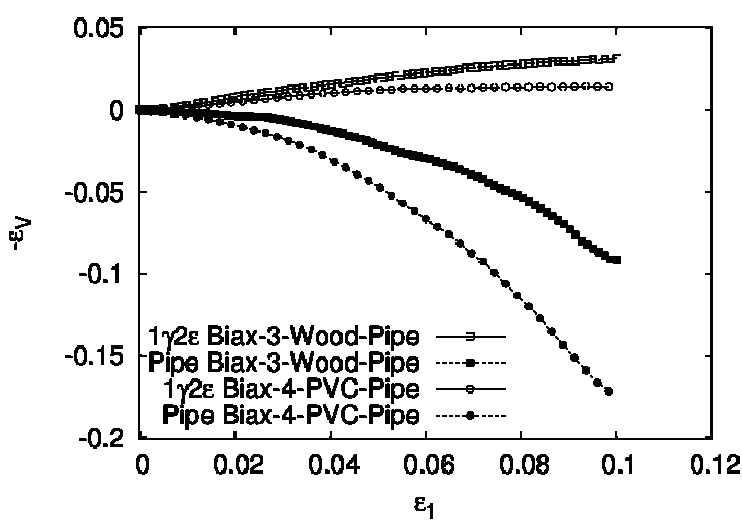

Fig. 6. During vertical compression test in $1 \gamma 2 \varepsilon$ the volumetric strains of the apparatus and the pipe specimen were different. The whole sample was dilating $\left(\varepsilon_{V}>0\right.$, two top curves) while the PVC pipe was contracting $\left(\varepsilon_{V}<0\right.$, two bottom curves)

\section{NUMERICAL MODELING}

The problem of an elastic pipe surrounded with granular material and subjected to loading was subsequently modeled numerically using DEM in the framework of Molecular Dynamics. The granular model used in the modeling was similar to the one described by Szarf et al. [13], [14] and consisted of particles called clumps made of three discs forming a single body. The shape of the particles was defined with a simple geometrical parameter

$$
\alpha=1-\frac{R_{2}}{R_{1}}
$$

that linked the radii of a smallest circumscribed circle and a largest inscribed circle of a particle, Fig. 8a. By changing the value of $\alpha$ it was possible to obtain many variations of the shape, Fig. $8 \mathrm{~b}$.

The introduction of the complex particle shapes instead of simple discs ensured that the mechanical behaviour of the granular material was more similar to the behaviour of real soil without the necessity of incorporating additional numerical devices such as rolling re-

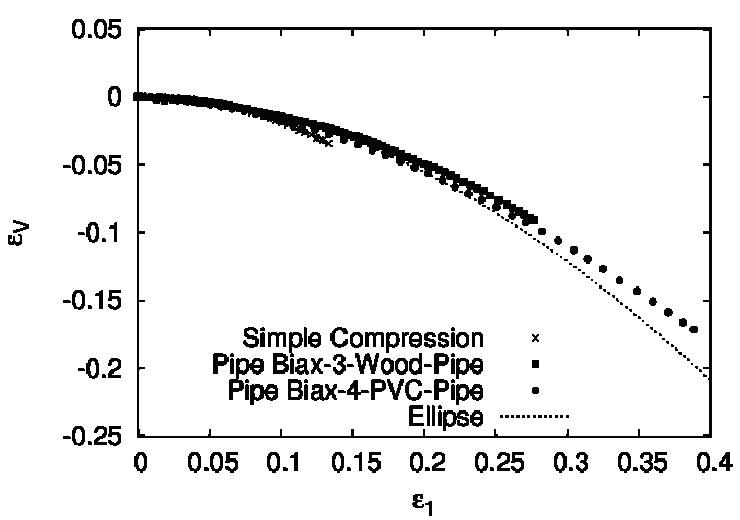

Fig. 7. Comparison of the volumetric strains between experiments on an flexible pipe with theoretical behaviour of an ellipse.

The vertical strains $\varepsilon_{1}$ are not the strains of the experimental apparatus as in Figs. 4 or 6 but the strains of the pipe

sistance. This allowed the numerical model to remain simple and to use classical DEM contact laws: linear elastic normal contact law and elastic-perfectly plastic tangential law (for more details see [13], [14]).

Apart from the granular material, a model of an elastic pipe made of 48 elastically connected discs was used as well. The mechanical behaviour of the pipe was governed by the introduction of the additional contact law called parallel bond $\left(\mathrm{PFC}^{2 \mathrm{D}} \mathrm{Man}-\right.$ ual [8]). A parallel bond is transferring compressive and tensile forces, as well as moments of force between the two connected particles. By default this law is acting together with the classical normal and tangential contact laws, which causes different behaviour in compression and tension. That was solved by countering the forces from the two classical contact laws in every pipe-pipe contact with additional opposite forces. Therefore it was possible to relate the numerical parameters of contact stiffness in the pipe to the geometry and Young's modulus of the real pipe

$$
k_{n}^{p b}=\frac{E}{D},
$$

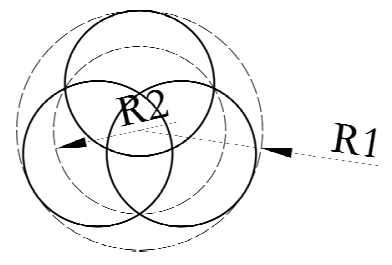

a) $\alpha$ definition;

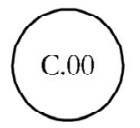

$\alpha \quad 0.00$
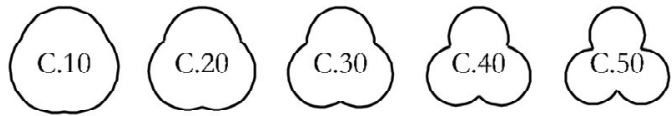

$0.10 \quad 0.20$
0.40

0.50

b) Particle shapes used

Fig. 8. Definition of the shape parameter $\alpha$ (left) and the shapes of particles with different values of $\alpha$ used in this study (right) 
where $k_{n}^{p b}$ is the normal stiffnesses of parallel bond contact, $D$ is the diameter of each disc forming the pipe, $E$ is Young's modulus of the pipe material. The stiffness of the pipe in numerical simulations was assumed to be equal to the stiffness of the pipe in the physical experiments. Young's modulus of the PVC pipe was assessed in a laboratory simple compression tests and was equal to $2 \mathrm{GPa}$. The parallel bonds in the pipe were modeled as unbreakable.

As in the case of physical experiments, the numerical simulations were performed both with and without the pipe in the granular sample. Each sample consisted of 5000 particles of a given shape and different radii $\left(R_{\max }=3 R_{\min }\right.$ with linear distribution of particle area in this range) placed as a granular gas in a rigid square box. The size of the particles was slowly increased up to a point when $\sigma=2.5 \mathrm{kPa}$. The samples were then compressed isotropically with rigid walls up to $\sigma=50.0 \mathrm{kPa}$ in absence of intergranular friction in order to obtain dense assemblies. Up to this point the deformations of the pipe were blocked. Samples prepared in such way were then subjected to vertical compression with very low velocity in order to avoid any dynamical effect while the lateral pressure on the walls was kept at $50 \mathrm{kPa}$, just as in the physical experiments. Vertical compression tests were performed with the presence of intergranular friction between the backfill particles. Gravity was neglected.

\subsection{RESULTS OF THE NUMERICAL MODELING IN DEM}

Comparison of the numerical vertical compression tests with and without a pipe made with different particle shapes revealed that, in contrary to the physical experiments, there was a persistent reduction of maximum macroscopic friction angle in the presence of elastic pipe, Fig. 9. The residual value of friction angle was unaffected.

Observation of the global volumetric strains of the whole assembly and the strains of the pipe revealed behaviour similar to the one in physical experiments: dilation of granular sample and contraction of the pipe.

The biggest advantage of numerical simulations in comparison with physical experiments is the access to the forces acting in the microscale between the particles of the medium. This made the assessment of load repartition possible. Apart from that, it was possible to test the effects of the pipe surface roughness by changing the microscopic friction angle coefficient $\mu^{\mathrm{pipe}}$ between 0.0 and 0.5 , and to perform additional vertical compression tests with pipe ten times more and ten times less stiff than the one used in the physical experiments.

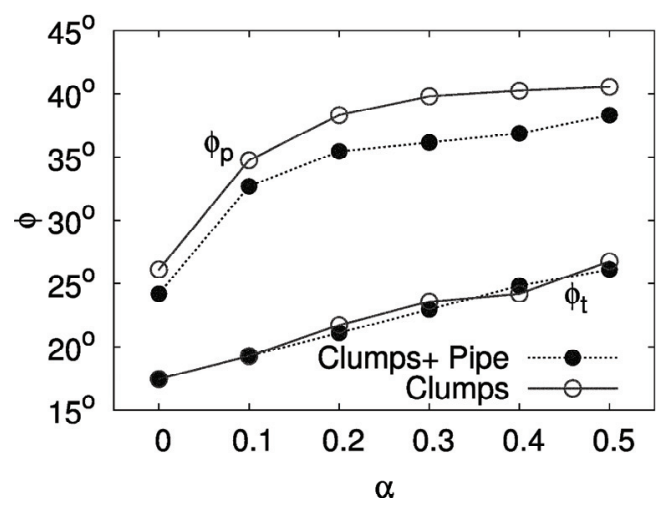

Fig. 9. Comparison of the peak $\varphi_{p}$ and residual $\varphi_{t}$ macroscopic friction angles obtained in numerical simulations with and without an elastic pipe buried in assemblies consisting of particles with different $\alpha$

In Fig. 10, the shapes of the loaded assemblies containing pipes of various stiffnesses are presented. Even thought the vertical strains of the assemblies are the same in each case, the pipes are clearly compressed to a different extent. Examination of the contact force networks for the three stiffnesses of the pipe show that while in case of rigid pipe the density of force chains is similar in every section of the assembly, in case of soft pipe there appears an arch-like structure and the force network at the sides of the pipe is more intensive. These observations were quantified by comparing the vertical load acting on the sample and on the pipe itself, Fig. 11 and Fig. 12.

In every case in the initial phase of the loading the load repartition occurred and disappeared in the later phases when the shear in granular assembly localised. The intensity of the repartition seems to depend on number of factors: The stiffness of the pipe is the most pronounced, with rigid pipe carrying more load; The shape of the soil particles influence the load transfer as well, with the most circular particles contributing very little while particles with deep concavities $(\alpha=0.5)$ transferring more (it should be noted that the change of particle shape influence the macroscopic friction angle of the assembly, see Fig. 9 and (Szarf et al. [13], [14]; CEGEO et al. [2]), so the effect is not straightforward); The presence of friction at the pipe boundary was observed to actually reduce the beneficial effect of load transfer. 

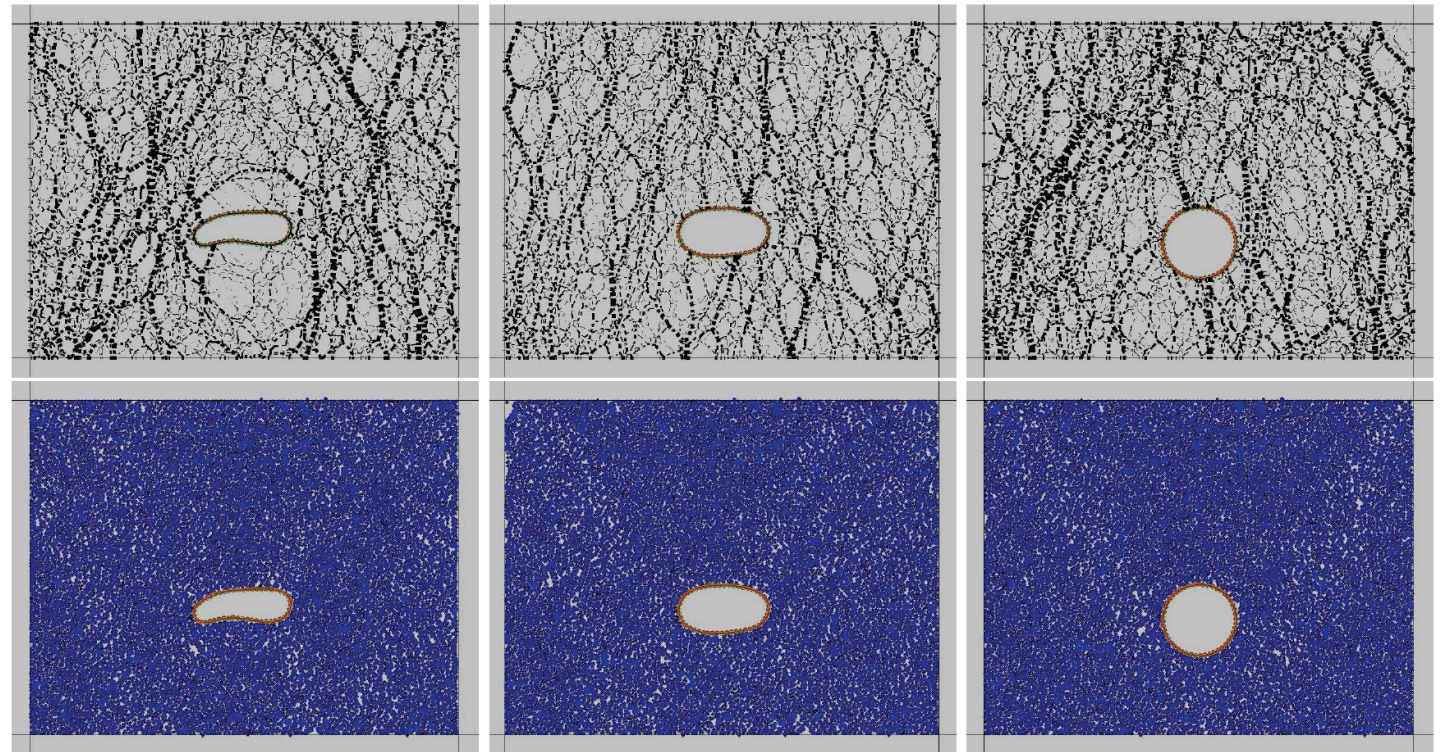

Fig. 10. View of the contact force network (top) and the whole assembly (bottom) at $\varepsilon_{1}=10 \%$ of vertical strains of the assembly. In the three simulations the stiffness of the pipe material was equal to $0.2 \mathrm{GPa}$ (left), $2.0 \mathrm{GPa}$ (center, the original stiffness)

and $20.0 \mathrm{GPa}$ (right). In every case the value of shape parameter of soil particles is equal to $\alpha=0.5$ and there is no friction at the boundary of the pipe

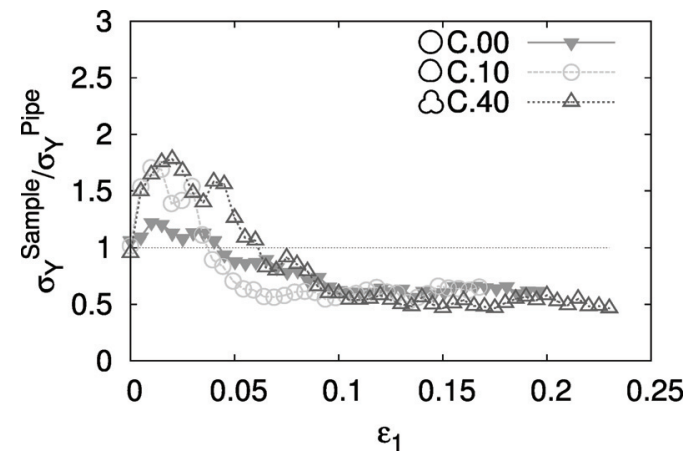

(a) Influence of particle shape, $E=2 \mathrm{GPa}, \mu^{\mathrm{pipe}}=0.0$;

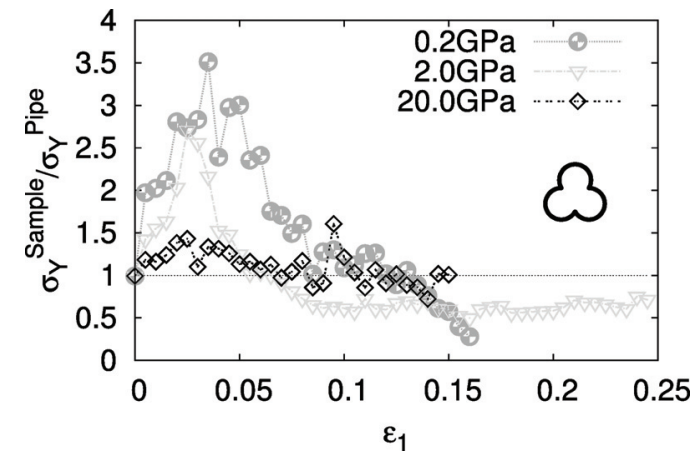

(b) Influence of pipe stiffness, $\alpha=0.5, \mu^{\text {pipe }}=0.0$

Fig. 11. Load repartition in vertical compression tests with elastic pipe.

Vertical stress acting on the sample is related to the vertical stress acting on the pipe. In the initial phases of loading, the pipe is loaded less than the backfill material

Fig. 12. Summary of maximum load repartition over flexible pipe for different particle shapes, different roughness of the pipe surface and different stiffness of the pipe

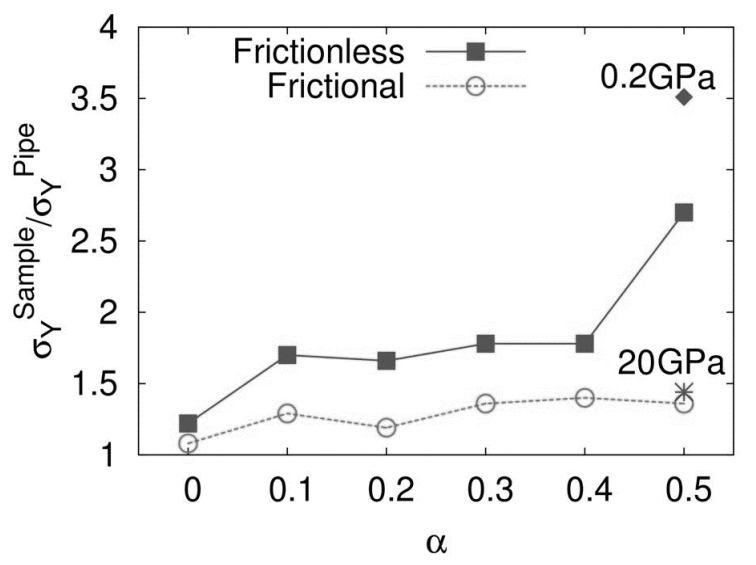




\section{CONCLUSIONS AND PERSPECTIVES}

This work devoted to the study of load transfer around buried flexible pipes made use of various techniques: laboratory experiments on analogue granular material, digital image correlation, numerical modeling in DEM. Even though the instrumentation of the experiment and the numerical model were simple, the combination of both proved to be an efficient method of studying the problems of load repartition. The experimental setup was reproduced numerically and the results obtained were comparable both at the macro and mezoscopic levels. Use of numerical tools enabled access to the microscale information as well. The study of intergranular forces revealed differences in loading of the underground pipe depending on a number of factors: particle shape, pipe stiffness and pipe roughness.

The framework of soil-structure interaction studying presented in this paper seems to be promising and should be continued to develop. The experimental setup used should be enhanced with more direct measurements in order to corroborate the numerical results further. The numerical model of the pipe was perfectly elastic and therefore too simple to simulate the real behaviour of elasto-plastic materials like PVC; Nevertheless, the comparison with the experimental results was satisfactory. The numerical model used is very flexible in terms of micromechanical parameters control and therefore can help solving many experimental limitations like delicate changes of material properties or problem geometry.

The study presented should be continued especially in the direction of real scale experiments. Apart from that, in order to deal with engineering problems the technical details like pipe laying procedure should be performed more realistically. Another drawback of that study was the limitation of particle size and number, both in physical and numerical tests, a problem which probably influence the performance of the buried pipe.

\section{REFERENCES}

[1] Calvetti F., Combe G., Lanier J., Experimental micromechanical analysis of a $2 D$ granular material: relation between structure evolution and loading path, Mechanics of Cohesive frictional Materials, 1997, 2(2), 121-163.
[2] Cegeo, Saint-Cyr B., Szarf K., Voivret C., AzÉma E., Richefeu V., Delenne J. Y., Combe G., Nouguier-Lehon C.,Villard P., Sornay P., Chaze M., Radjai F., Particle shape dependence in $2 D$ granular media, EPL (Europhysics Letters), 2012, 98, 44008.

[3] Charalampidou E.M., Combe G., Viggiani G., Lanier J., Mechanical behavior of mixtures of circular and rectangular 2D particles, Powders and Grains, 2009, 821.

[4] Desrues J., Viggiani G., Strain localization in sand: an overview of the experimental results obtained in Grenoble using stereophotogrammetry, International Journal for $\mathrm{Nu}-$ merical and Analytical Methods in Geomechanics, 2004, 28(4), 279-321.

[5] Hall S.A., Wood D.M., IBRAIM E., Viggiani G., Localised deformation patterning in $2 D$ granular materials revealed by digital image correlation, Granular Matter, 2010, 12(1), $1-14$.

[6] Joer H., Lanier J., Desrues J., Flavigny E., $1 \gamma 2 \varepsilon$ : A new shear apparatus to study the behavior of granular materials, Geotechnical Testing Journal, 1992, 15.

[7] Lirer S., Flora A., Lanier J., Viggiani G., Analisi sperimentale dell'influenza della forma delle particelle sul comportamento di un materiale granulare $2 D$, [in:] Incontro annuale ricercatori di geotecnica, 19-30 June 2005, Ancona, Italy, 2005.

[8] PFC2D Manual, PFC2D Particle Flow Code in 2 Dimensions - Theory and Background, Version 3.1. Itasca Consulting Group, Inc. 2004.

[9] Richefeu V., Combe G., Viggiani G., An experimental assessment of displacement fluctuations in a $2 D$ granular material subjected to shear, Géotechnique Letters, 2012, 2(July-September), 113-118.

[10] SCHNEEBELI G., Une analogie mécanique pour les terres sans cohésion, Comptes rendus de l'académie des sciences, 1956, 243, No. 1, 125-126.

[11] Sibille L., Froilo F., A numerical photogrammetry technique for measuring microscale kinematics and fabric in Schneebeli materials, Granular Matter, 2007, 9(3-4), 183-193.

[12] Sutton M.A., Orteu J.-J., Schreier H., Image Correlation for Shape, Motion and Deformation Measurements: Basic Concepts, Theory and Applications, Springer Publishing Company, Incorporated, 1st ed., 2009.

[13] Szarf K., COMBe G., Villard P., Influence of grain shape on the mechanical behaviour of granular materials, In Colloque "Science et Technologie des Poudres et Matériaux Frittés 2009" (STPMF), 25-27 May 2009, Montpellier, France, 2009.

[14] Szarf K., Combe G., Villard P., Polygons vs. clumps of discs: A numerical study of the influence of grain shape on the mechanical behaviour of granular materials, Powder Technology, 2011, 208(2), 279-288. Special Issue: Papers presented to the Symposium STPMF 2009, Science and Technology of Powders and Sintered Materials. 